NASA/TM-2002-211723

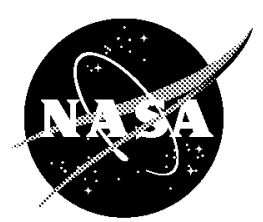

\title{
Unsteady Pressures in a Transonic Fan Cascade Due to a Single Oscillating Airfoil
}

J. Lepicovsky

QSS Group, Inc., Cleveland, Ohio

E.R. McFarland

Glenn Research Center, Cleveland, Ohio

V.R. Capece and J. Hayden

University of Kentucky, Paducah, Kentucky 
The NASA STI Program Office ... in Profile

Since its founding, NASA has been dedicated to the advancement of aeronautics and space science. The NASA Scientific and Technical Information (STI) Program Office plays a key part in helping NASA maintain this important role.

The NASA STI Program Office is operated by Langley Research Center, the Lead Center for NASA's scientific and technical information. The NASA STI Program Office provides access to the NASA STI Database, the largest collection of aeronautical and space science STI in the world. The Program Office is also NASA's institutional mechanism for disseminating the results of its research and development activities. These results are published by NASA in the NASA STI Report Series, which includes the following report types:

- TECHNICAL PUBLICATION. Reports of completed research or a major significant phase of research that present the results of NASA programs and include extensive data or theoretical analysis. Includes compilations of significant scientific and technical data and information deemed to be of continuing reference value. NASA's counterpart of peerreviewed formal professional papers but has less stringent limitations on manuscript length and extent of graphic presentations.

- TECHNICAL MEMORANDUM. Scientific and technical findings that are preliminary or of specialized interest, e.g., quick release reports, working papers, and bibliographies that contain minimal annotation. Does not contain extensive analysis.

- CONTRACTOR REPORT. Scientific and technical findings by NASA-sponsored contractors and grantees.
- CONFERENCE PUBLICATION. Collected papers from scientific and technical conferences, symposia, seminars, or other meetings sponsored or cosponsored by NASA.

- SPECIAL PUBLICATION. Scientific, technical, or historical information from NASA programs, projects, and missions, often concerned with subjects having substantial public interest.

- TECHNICAL TRANSLATION. Englishlanguage translations of foreign scientific and technical material pertinent to NASA's mission.

Specialized services that complement the STI Program Office's diverse offerings include creating custom thesauri, building customized data bases, organizing and publishing research results... even providing videos.

For more information about the NASA STI Program Office, see the following:

- Access the NASA STI Program Home Page at http://wwo.sti.nasa.gov

- E-mail your question via the Internet to help@stinasa.gov

- Fax your question to the NASA Access Help Desk at 301-621-0134

- Telephone the NASA Access Help Desk at 301-621-0390

- Write to: NASA Access Help Desk NASA Center for AeroSpace Information 7121 Standard Drive Hanover, MD 21076 
NASA/TM-2002-211723

GT-2002-30312

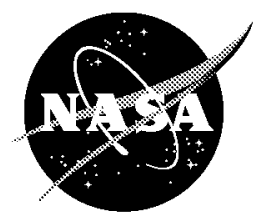

\section{Unsteady Pressures in a Transonic Fan Cascade Due to a Single Oscillating Airfoil}

J. Lepicovsky

QSS Group, Inc., Cleveland, Ohio

E.R. McFarland

Glenn Research Center, Cleveland, Ohio

V.R. Capece and J. Hayden

University of Kentucky, Paducah, Kentucky

Prepared for the

Turbo Expo 2002

cosponsored by the American Society of Mechanical Engineers

and the International Gas Turbine Institute

Amsterdam, The Netherlands, June 3-6, 2002

National Aeronautics and

Space Administration

Glenn Research Center

July 2002 


\section{Acknowledgments}

This work was sponsored by the NASA Glenn Research Center under the Smart Engine Components Project managed by Mr. R.D. Corrigan as a part of the R\&T Base Propulsion and Power Program. The authors would like to thank Mrs. L. Shaw, Chief, Compressor Branch, for her continuous support.

The Aerospace Propulsion and Power Program at NASA Glenn Research Center sponsored this work.

Available from

NASA Center for Aerospace Information 7121 Standard Drive

Hanover, MD 21076
National Technical Information Service 5285 Port Royal Road Springfield, VA 22100

Available electronically at http://gltrs.grcnasa.gov 


\title{
UNSTEADY PRESSURES IN A TRANSONIC FAN CASCADE DUE TO A SINGLE OSCILLATING AIRFOIL
}

\author{
J. Lepicovsky \\ QSS Group, Inc., \\ Cleveland, Ohio 44135 \\ E.R. McFarland \\ National Aeronautics and Space Administration \\ Glenn Research Center \\ Cleveland, Ohio 44135 \\ V.R. Capece and J. Hayden \\ University of Kentucky \\ Paducah, Kentucky 42002
}

\section{ABSTRACT}

An extensive set of unsteady pressure data was acquired along the midspan of a modern transonic fan blade for simulated flutter conditions. The data set was acquired in a nine-blade linear cascade with an oscillating middle blade to provide a database for the influence coefficient method to calculate instantaneous blade loadings. The cascade was set for an incidence of $10 \mathrm{dg}$. The data were acquired on three stationary blades on each side of the middle blade that was oscillated at an amplitude of $0.6 \mathrm{dg}$. The matrix of test conditions covered inlet Mach numbers of $0.5,0.8$, and 1.1 and the oscillation frequencies of $200,300,400$, and $500 \mathrm{~Hz}$. A simple quasi-unsteady two-dimensional computer simulation was developed to aid in the running of the experimental program. For high Mach number subsonic inlet flows the blade pressures exhibit very strong, low-frequency, selfinduced oscillations even without forced blade oscillations, while for low subsonic and supersonic inlet Mach numbers the blade pressure unsteadiness is quite low. The amplitude of forced pressure fluctuations on neighboring stationary blades strongly depends on the inlet Mach number and forcing frequency. The flowfield behavior is believed to be governed by strong nonlinear effects, due to a combination of viscosity, compressibility, and unsteadiness. Therefore, the validity of the quasi-unsteady simplified computer simulation is limited to conditions when the flowfield is behaving in a linear, steady manner. Finally, an extensive set of unsteady pressure data was acquired to help development and verification of computer codes for blade flutter effects.
NOMENCLATURE

\begin{tabular}{|c|c|c|}
\hline C & {$[\mathrm{mm}]$} & blade chord \\
\hline$c_{p}$ & {$[1]$} & pressure coefficient $\left\{\left(p_{\xi}-p\right) /\left(\rho v^{2} / 2\right)\right\}$ \\
\hline$f$ & {$[\mathrm{~Hz}]$} & frequency \\
\hline$f_{\mathrm{RED}}$ & {$[1]$} & reduced frequency \\
\hline$h$ & {$[\mathrm{~mm}]$} & blade height \\
\hline$i_{\mathrm{GM}}$ & {$[d g]$} & geometry incidence \\
\hline$M a_{\mathbb{N}}$ & {$[1]$} & cascade inlet Mach number \\
\hline$p$ & {$[k P a]$} & static pressure \\
\hline$s$ & {$[\mathrm{~mm}]$} & blade pitch \\
\hline$v$ & {$[\mathrm{~m} / \mathrm{s}]$} & flow velocity \\
\hline$x$ & {$[\mathrm{~mm}]$} & axial distance \\
\hline$\gamma$ & {$[d g]$} & stagger angle \\
\hline$\theta$ & {$[d g]$} & leading edge camber angle \\
\hline$\rho$ & {$\left[\mathrm{kg} / \mathrm{m}^{3}\right]$} & air density \\
\hline$\sigma$ & {$[\mathrm{kPa}]$} & pressure standard deviation \\
\hline$\tau$ & {$[m s]$} & time \\
\hline ל & {$[\mathrm{mm}]$} & chordwise distance \\
\hline
\end{tabular}

\section{INTRODUCTION}

Modern turbofan engines employ a highly-loaded fan stage with transonic or low-supersonic relative velocities in the blade-tip region. The fan blades have low aspect ratio and wide chord with tip-section airfoils designed for precompression. A typical tip-section airfoil is shown in Fig. 1 and cascade parameters are given in Tab. 1 (Refs. 1,2). The airfoil has a sharp leading edge with negative camber that 
makes them prone to flow separation at high incidence angles when engines are forced to operate near the stall flutter boundary of the fan. Induced blade flutter and associated high cycle fatigue problems are very detrimental to the engine health. Stall flutter and particularly blade life prediction codes are not yet fully reliable; their verification is hampered by a lack of reliable unsteady loading data, particularly for the airfoils in question. Interest in fan blade stall flutter research has increased in recent years. The goal of the current work is

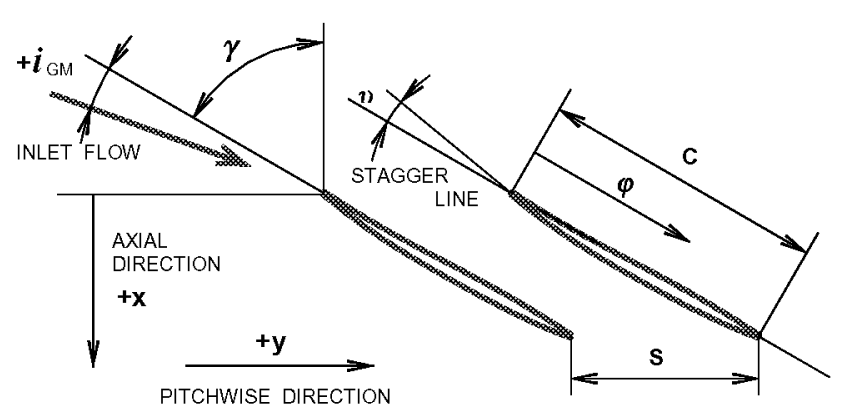

Fig. 1 Tip-section airfoil and cascade coordinate system.

\begin{tabular}{|ll|c|}
\hline Blade chord, & $C$ & $89.2 \mathrm{~mm}$ \\
\hline Leading edge camber angle, & $v$ & $29.5 \mathrm{dg}$ \\
\hline Maximum thickness, & $\boldsymbol{t}$ max & $0.048 \mathrm{C}$ \\
\hline Location of maximum thickness, & $\varphi_{\max }$ & $0.625 \mathrm{C}$ \\
\hline Stagger angle, & $\gamma$ & $60.0 \mathrm{dg}$ \\
\hline Number of blades in the cascade & 9 \\
\hline Blade pitch, & $S$ & $58.4 \mathrm{~mm}$ \\
\hline Cascade solidity, & $C / S$ & 1.53 \\
\hline Pitching axis, & $\varphi_{\mathrm{ax}}$ & $0.5 \mathrm{C}$ \\
\hline Blade height, & $\boldsymbol{h}$ & $95.9 \mathrm{~mm}$ \\
\hline
\end{tabular}

Tab. 1 Airfoil and cascade parameters.

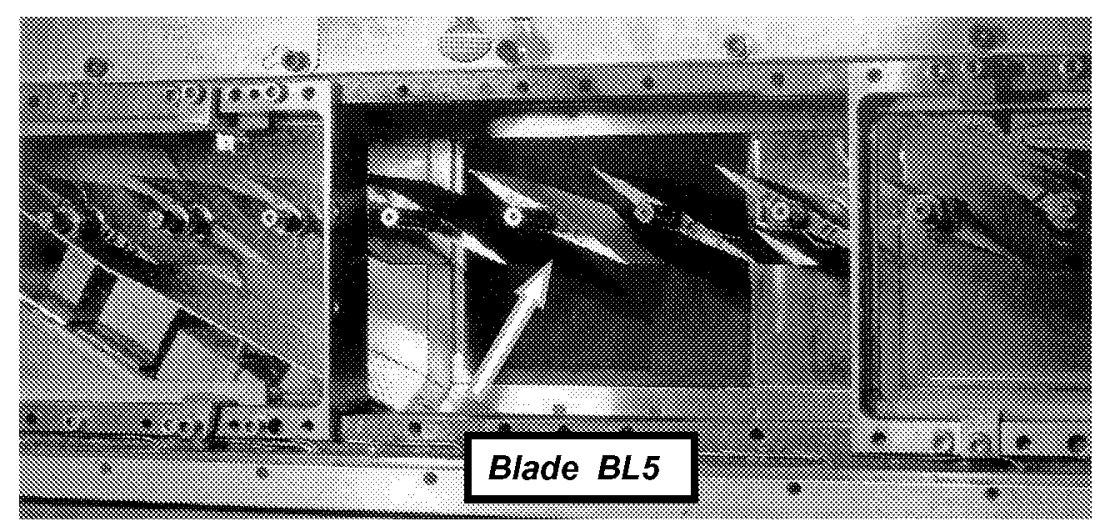

Fig. 2 Test section of the NASA Transonic Flutter Cascade. to acquire reliable aerodynamic data at conditions that simulate blade flutter on modern fan airfoils to verify and calibrate prediction codes for unsteady behavior of transonic fan blades.

\section{TEST FACILITY}

The NASA GRC Transonic Flutter Cascade (TFC) is one of a very few test facilities dedicated to the unsteady aerodynamics of oscillating airfoils. The facility combines a linear cascade wind tunnel with a high-speed drive system that imparts pitching oscillations to any single or all cascade blades (Refs. 3,4 ). The cascade consists of nine blades. A view of the cascade test section is in Fig. 2. Previous test programs to study stall flutter that have been conducted in this facility were reported in references 1 and 5 . These data were acquired at Mach numbers of 0.5 and 0.8 , and chordal, geometric incidence angles of $0 \mathrm{dg}$ and $10 \mathrm{dg}$. Data from these programs proved to have some irregularities. To improve the quality of data taken in the facility, a systematic experimental and computational study (Refs. 2, 6, 7) was carried out that helped to explain several discrepancies in the older data sets, particularly the questions of actual flow incidence angles and the inconsistency between predicted and measured backpressure levels. The flow path of the facility was modified which resulted in significant improvement of the flowfield uniformity and blade loading periodicity. A high degree of blade load uniformity now extends over six blades from blade BL2 to blade BL7.

\section{EXPERIMENTAL APPROACH}

The unsteady data, reported in references 1 and 5 , were acquired using the traveling wave method with all nine blades in the cascade oscillating at a constant interblade phase angle. For the large mean incidence angle, a separation bubble forms at the leading edge region of the suction surface as shown in Fig. 3. The flow pattern in the separated flow region was acquired using a dye-oil surface flow visualization technique (Ref. 8). The separation bubble destabilizes flow in the leading edge region, which probably resulted in instabilities for the $180 \mathrm{dg}$ interblade phase angle as reported in Refs. 1 and 5. Experimental results at other interblade phase angles were judged to be unrealistic. This was most likely due to tunnel sidewall reflections and a lack of cascade periodicity that interfered with the cascade unsteady aerodynamics (Ref. 9). 


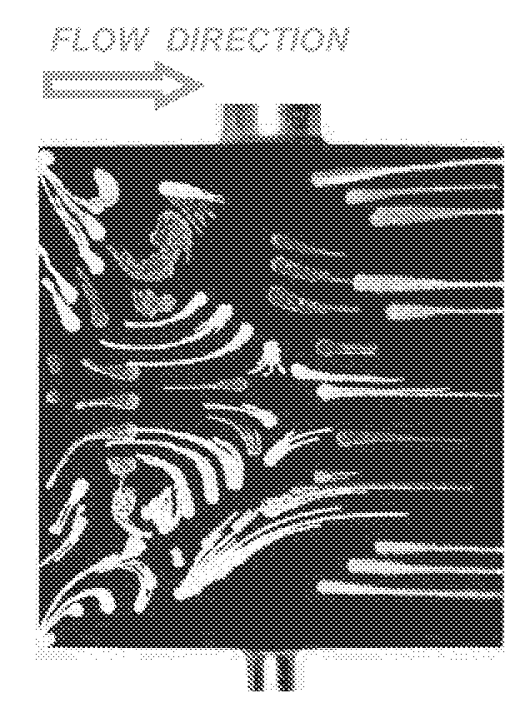

Fig. 3. Suction side surface flow pattern for $M a_{\mathbb{N}}=0.80$ and $i_{\mathrm{GM}}=10.0 \mathrm{dg}$.



Fig. 4. Blade KP1 instrumented with 15 Kulite transducers.
This will be validated quantitatively by verifying the dynamic periodicity of the airfoils in the central portion of the cascade. An oscillation amplitude of $0.6 d g$ will be used, because for small amplitude the unsteady flow is assumed to be linear. To quantify the influence of oscillation amplitude these experiments will be repeated for larger oscillation amplitudes of 1.2 and $2.4 d g$.

By using the influence coefficient technique interblade phase angles will be achievable that were not previously possible. This will allow the attainment of experimental data to further our understanding of the flow physics for unsteady separated flow.
The contamination by signal reflections can be reduced by not oscillating the blades next to the tunnel walls. The technique of influence coefficients requires only one blade in the cascade to oscillate, and therefore it has the potential to reduce this contamination. The method is based on the superposition principle for linear systems. For this case the unsteady pressures on an airfoil for a given cascade geometry, reduced frequency, and inlet flow condition are separated into a contribution of the airfoil oscillating on itself and a separate contribution from the oscillation of each neighboring airfoil. This technique requires a high degree of flow periodicity within the cascade for a larger number of blades.

The influence coefficient method has been used numerically and experimentally for attached flows. It was shown numerically for a compressor blade in supersonic inviscid flow that the influence coefficient method using seven blade passages gives nearly equivalent first harmonic pressure coefficient results as the traveling wave method (Ref. 10). The method was validated experimentally for biconvex airfoils in a linear cascade (Ref. 11) and for a turbine annular cascade (Refs. 12, 13). The results have indicated the validity of this method for attached flow for cases with negligible influence of tunnel sidewalls and for unsteady flows that are not in the vicinity of acoustic resonance.

The method of influence coefficients has not been investigated in detail for separated flow. To validate it for flows with separations, the unsteady pressures will first be acquired on cascade blades for a single oscillating blade. Then, the unsteady pressures will be acquired for conditions when all blades in the cascade are oscillating. However, the cascade will be operated at interblade phase angles where the effects of acoustic wall reflections on the measured unsteady pressures are minimized.

\section{INSTRUMENTATION AND DATA ACQUISITION}

Six blades were instrumented: two blades with conventional static taps (blades S1, P1), and four blades with customized miniature high-frequency pressure transducers, Kulite XCQ-062-15A, with a nominal range of 0 to $100 \mathrm{kPa}$ absolute (blades KS1, KS2, KP1, KP2). Each blade had 15 ports along the midspan line either on the suction or pressure surface. The transducers for blades KS1 and KP1 had an average sensitivity of $1.3 \mathrm{mV} / \mathrm{kPa}$ and those for blades KS2 and $\mathrm{KP} 2 \mathrm{had}$ an average sensitivity of $0.6 \mathrm{mV} / \mathrm{kPa}$. Fig. 4 shows the fully instrumented blade KP1. Unfortunately, a number of transducers failed for various reasons, mostly due to problems with wire splicing at the blade shaft. The instrumentation arrangement did not allow repairing individual sensors and consequently data is not available for all instrumented ports.

The steady state data were acquired using the NASA lab wide system ESCORT (Ref. 14). The unsteady data acquisition system (UDAS) is based on the National Instruments (NI) system, PXI-1010, with an embedded computer PXI-8156B with a $333 \mathrm{MHz}$ Intel Pentium processor and a $4 G B$ hard drive. Two NI 6071E analog/digital (A/D) boards are used. Each board accepts 64 single-ended analog inputs; therefore up to 32 Kulite transducers can be connected to a board. The board has 12-bit resolution. The scanning frequency is $1.25 \mathrm{MHz}$, which allows sampling $32 \mathrm{Kulite}$ transducers with frequencies up to $39 \mathrm{kHz}$. Each Kulite transducer had its own dedicated signal conditioner, Endevco $4430 \mathrm{~A}$, with a precision DC bridge amplifier and built-in constant excitation voltage/current supply. Signal amplifiers were set for a DC amplification of 50 for blades KS1 and KP1, and 100 for blades KS2 and KP2. Low pass filters and zero offsets were disabled. 
The UDAS was controlled by in-house developed software. Data acquisition time for each test point was $3150 \mathrm{~ms}$, which is 120,000 samples. In order to maintain the high speed of data sampling of $38 \mathrm{kHz}$, the A/D boards were operated one at a time. Therefore, two sets of data were acquired for each cascade operating condition, one for blades KS1 and KS2, and the other set for blades KP1 and KP2.

The timing of data acquisition is depicted in Fig. 5. It is identical for both A/D boards. The elapsed time is shown on the horizontal axis, and the sequence of 32 channels per board on the vertical axis. The first signal is the once per period (OPP) data from an optical encoder that monitors rotation of a camshaft that drives the blade oscillations. The following 15 signals are pressure data from the first blade. Channel 17 on this board records a signal from an accelerometer (ACM) that is located on the tip shaft of blade BL5. This signal verifies angular position of the oscillating blade. The remaining 15 channels are pressure data from the second blade. Time difference between any two channels is $0.8 \mu \mathrm{s}$, which is governed by the $1.25 \mathrm{MHz}$ scanning frequency. It takes $24.8 \mu \mathrm{s}$ to record pressure data from both blades including OPP and ACM signals. The remaining $1.5 \mu \mathrm{s}$ the system idles to complete the time period of $26.3 \mu \mathrm{s}$, which corresponds to the sampling frequency of $38 \mathrm{kHz}$. This cycle is repeated 120,000 times to complete one test point. The length of a record for one test point is $3000 \mathrm{~ms}$. This allocation scheme was maintained during the entire test program. Even if a transducer was lost, the timing sequence stayed the same, and the faulty transducer data was removed only during the postprocessing procedures.

\section{DATA REDUCTION PROCEDURES}

Transducer calibration. Signals from Kulite transducers were recorded as voltage outputs using DC amplifiers because the high resolution of the $\mathrm{A} / \mathrm{D}$ board allowed retrieving information about steady-state pressure values as well as the pressure fluctuations during postprocessing. The resulting pressure resolution is better than $24 \mathrm{~Pa}$. For comparison, the labwide steady state data recording system ESCORT has a resolution of $20 \mathrm{~Pa}$ for $100 \mathrm{kPa}$ transducers. By comparing the average absolute pressure levels with levels recorded by conventional static taps, it is possible to assess reliably the accuracy of measured pressure fluctuations.

Extensive calibration tests of transducers embedded in the instrumented blades were carried out in a vacuum chamber. The calibration results showed that the calibration constants drift a little. The slope of the calibration curves is relatively stable; the scatter is about $0.2 \%$ of the full scale (FS) value, which is $200 \mathrm{~Pa}$. The scatter of zero offsets shows a larger value, up to $0.6 \%$ of FS $(600 \mathrm{~Pa})$. However, it is possible to correct for the zero shift by reading new 'zeros' prior to each test and using them in the pressure conversion.

Signal treatment. Signals from pressure transducers are of low voltage, and thus are very sensitive to contamination due to electric ground loops and radio frequencies. The arrangement in the test cell did not allow putting amplifiers close to transducers. All precautions were made to eliminate ground loops and properly shield all signal carrying wires; nevertheless, some signals exhibited contamination and spurious spikes that could not be associated with flowfield pressure changes. Raw voltage signals were treated to eliminate most of the data contamination. The data reduction process consisted of the following four procedures: voltage/pressure signal conversion, data clipping, data patching, and zero drift correction.

Voltage/pressure conversion. This procedure retrieves voltage data for a selected port from a binary raw data file and converts it to pressures using prerecorded calibration constants for each transducer. Fig. 6 shows a $1000-\mathrm{ms}$ segment of a raw signal converted to pressure data.

Data clipping. This procedure eliminates single point overshoots. It was estimated that the actual pressure change between any two consecutive samples cannot be larger than $2.0 \mathrm{kPa}$

Fig. 5. Data acquisition timing diagram. 
for the sampling frequency of $38 \mathrm{kHz}$. The procedure removes overshoots and replaces them with an average of its pre- and post-neighbors. The clipping procedure does not affect the timing of the data sequence. A clipped signal is in Fig. 7.

Data patching. This procedure corrects for temporary signal dropouts exhibited occasionally by some of the transducers. Reasons for this behavior are still uncertain,

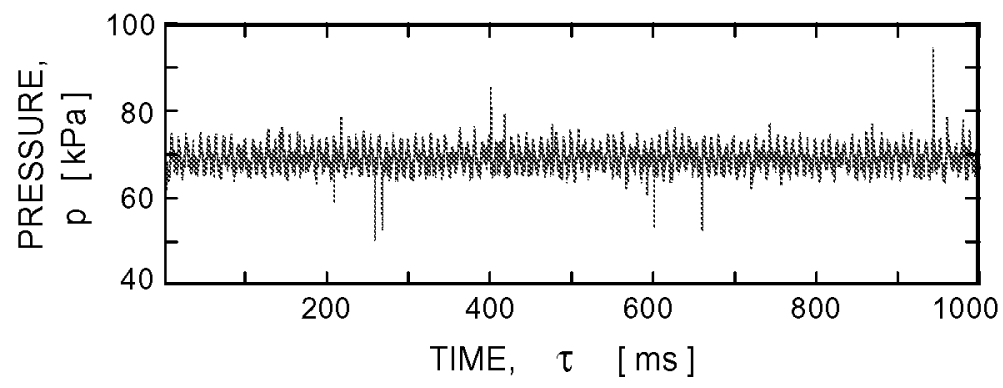

Fig. 6 Data signal heavily contaminated by 'single point 'spikes.

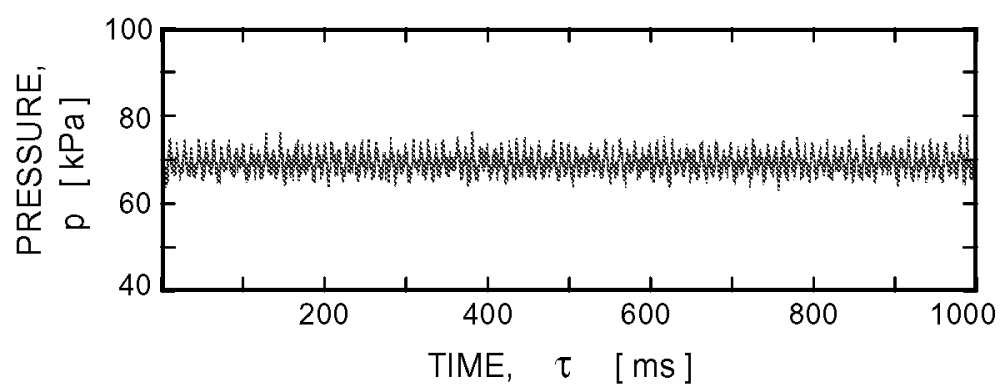

Fig. 7 Data signal treated by the clipping procedure.

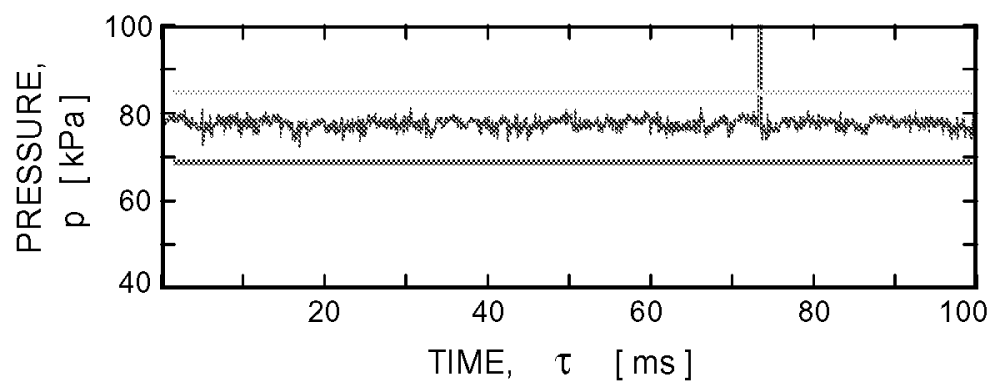

Fig. 8 Upper and lower pressure thresholds.

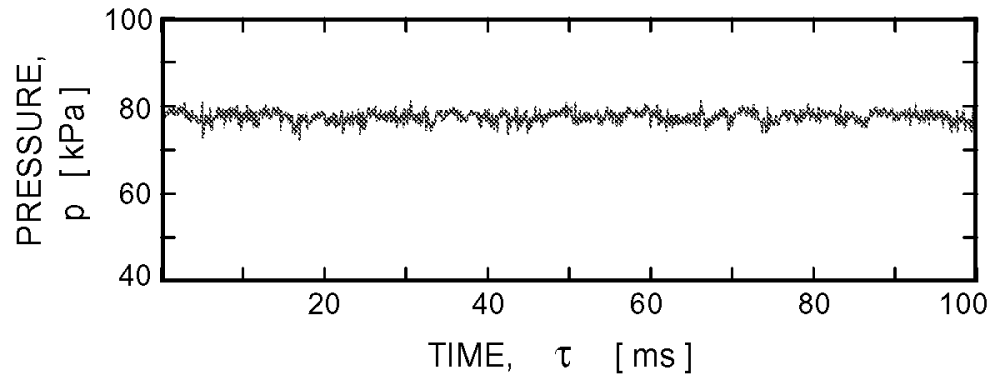

Fig. 9 Data signal treated by the patching procedure. perhaps momentary disruptions of continuity in the transducer circuitry that caused amplifier saturation. An example is in Fig. 8. The patching procedure removes signal segments that exceed the preset thresholds. The missing portion is replaced with a straight line connecting the endpoints of the patch, as shown in Fig. 9. This procedure does not alter the timing of the data sequence. The saturation dropouts extend only over a few percent of the data collection interval, therefore the effects on the variance of the signal are insignificant.

Zero drift correction. This procedure corrects pressure values for daily drifts of transducers' zeros. Zeros were recorded for all transducers before each test. This procedure affects only the pressure average value; amplitude of pressure fluctuations is not altered at all. This correction noticeably improves the accuracy of the time average pressures as documented in Fig. 10. The plots show pressure coefficient distributions over a suction surface of the cascade blade BL4 for the inlet Mach numbers 0.5 and 0.8 . The data comparison between the conventional tap data and four Kulite data sets is very good. The maximum difference between the static tap and averaged Kulite data is less than $2 \%$ of the local dynamic pressure value for Mach number 0.5 , and about $5 \%$ of the local dynamic pressure value for Mach number 0.8 . In terms of absolute local pressure values the tap/Kulite agreement is within $0.4 \%$ for Mach number 0.5 , and $3.4 \%$ for Mach number 0.8 . The good accuracy of Kulite averaged pressures is a measure of accuracy for pressure fluctuations of unsteady data. It is estimated that the accuracy of the pressure fluctuation amplitude measured by Kulite transducers is better than $4 \%$ of the local pressure amplitude.

\section{NATURE OF UNSTEADY PRESSURE DATA}

Samples of pressure histories for various inlet Mach numbers and blade oscillation frequencies will illustrate the nature of unsteady pressure data acquired on blade surfaces. Examples shown are for a transducer at port 15 , located on the suction surface at the trailing edge of blade BL4 (Fig. 11). The blade is just on the left of blade BL5, which was oscillated at an amplitude of $0.6 \mathrm{dg}$.

The effects of blade oscillation frequency (blade BL5) for an inlet Mach number of 0.5 are shown in Fig. 12. The segments of $100 \mathrm{~ms}$ long pressure data show cases of no oscillations and oscillations of 200 , and $400 \mathrm{~Hz}$. The case of no blade oscillations shows contamination by the net modulation of $60 \mathrm{~Hz}$. The peak-to-peak variation is about $2 \mathrm{kPa}$. For the cases when the middle blade was oscillated, 


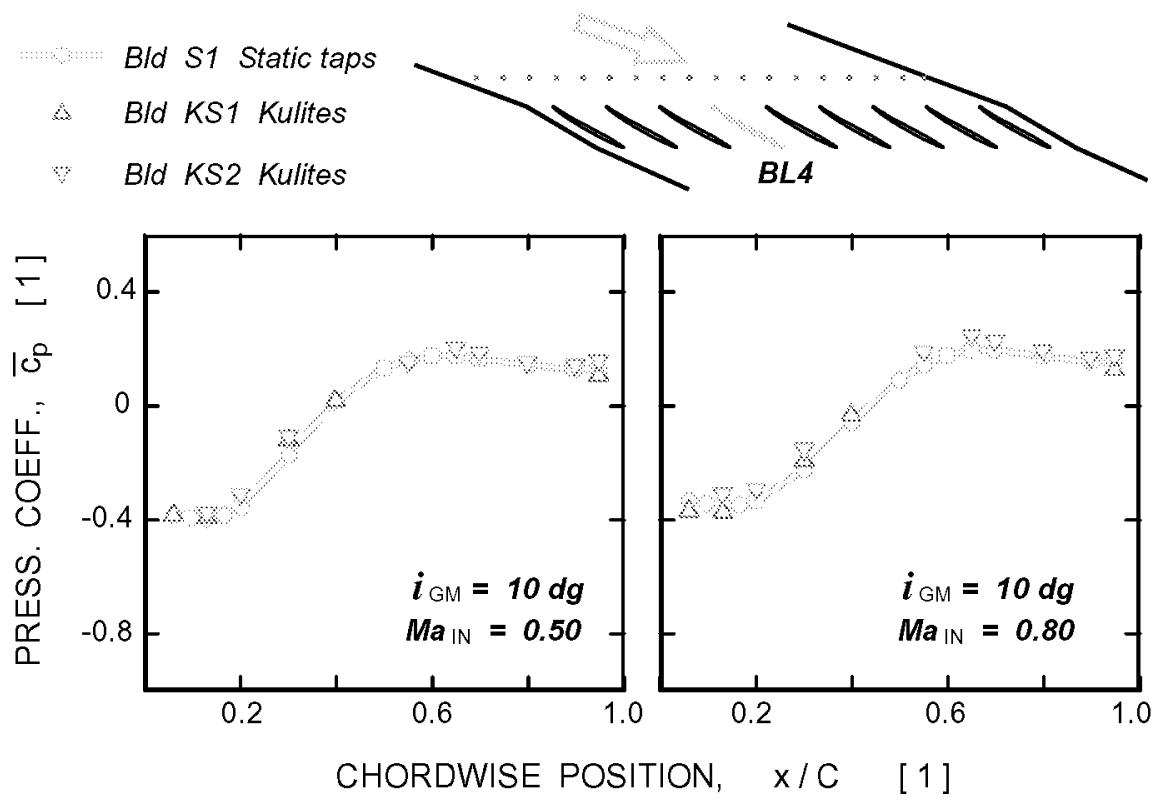

Fig. 10. Comparison of static tap data with Kulite average pressure data for the suction side of blade BL4. in the flow at this tunnel operating condition. The origin of these fluctuations is uncertain. It could be a tunnel effect or a consequence of instability in the separated flow region just downstream of the airfoil leading edge

Introducing blade oscillations of $200 \mathrm{~Hz}$ does not visibly change the character of the signal. For higher frequencies of blade BL5 oscillations, the effects of blade oscillations are traceable. In particular, for the highest blade frequency, a modulation of $500 \mathrm{~Hz}$ is superimposed on the signal and is visible. The peak-to-peak variation of $500-\mathrm{Hz}$ modulation is about $5 \mathrm{kPa}$. This is evident in the spectrum presented in Fig. 16, which shows the $110 \mathrm{~Hz}$ frequency and its harmonics along with the $500 \mathrm{~Hz}$ oscillation frequency.

Finally, data for the highest inlet Mach number of 1.08 are shown in Fig. 17. First, the pressure signal for the case of no oscillations exhibits weak contamination

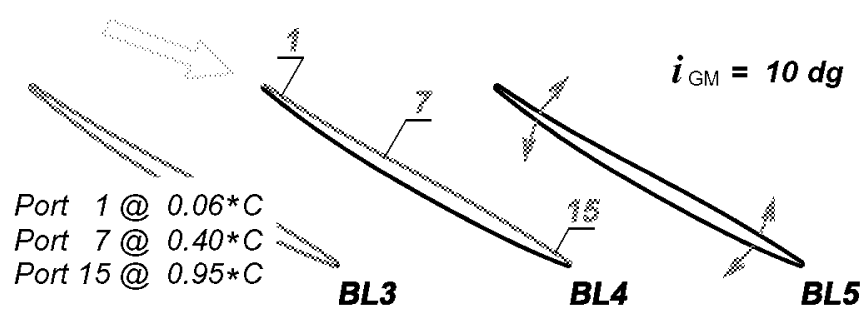

Fig. 11. Location of Kulite transducers on suction surface of blade BL4.

the effects of forced oscillations are barely traceable for the blade frequency of $200 \mathrm{~Hz}$; however, they are clearly visible for the $500 \mathrm{~Hz}$ blade frequency case. The peak-to-peak variation of the forced signal modulation is quite small, about $2 \mathrm{kPa}$.

The situation for the subsonic inlet Mach number of 0.8 is noticeably different, as depicted in Fig. 13. This figure shows the signal for no blade oscillations exhibits very strong periodic pressure fluctuations with a peak-to-peak variation of $11 \mathrm{kPa}$. Fig. 14 presents a spectral analysis of this transducer, which shows a large pressure fluctuation exists at $110 \mathrm{~Hz}$ with smaller second and third harmonics of this fundamental frequency. This phenomenon exists on all the transducers on blade BL4. For example, the spectrum for the transducer at port 1, as illustrated in Fig. 15, also shows that this pressure fluctuation is occurring at the blade leading edge. Furthermore, these pressure fluctuations were found to exist on the suction surface of other blades within the cascade at this inlet Mach number. It appears that these strong pressure fluctuations are induced due to modulation by the net frequency of $60 \mathrm{~Hz}$. Peak-to-peak variation of the signal contamination is about $2 \mathrm{kPa}$. The distributions acquired for blade BL5 oscillating show very strong modulation due to the oscillating blade frequency. The peak-to-peak variations of the modulated signal is $9 \mathrm{kPa}$ for a frequency of $200 \mathrm{~Hz}$, and about $7 \mathrm{kPa}$ for the case of $400 \mathrm{~Hz}$.

Changes in the character of the unsteady pressure signal from port to port along the blade chord are shown in Fig. 18 for the case of a supersonic inlet Mach number of 1.08 and the forcing frequency of $400 \mathrm{~Hz}$. The first pressure distribution is for port 1, which is very close to the blade leading edge. The signal is very clean, uncontaminated, and correctly shows no effects of the oscillating blade BL5; for the supersonic inlet condition any pressure fluctuations generated at the leading edge of blade BL5 cannot propagate to the leading edge region of blade BL4. Signal from port 7 shows the effects of forced pressure modulation. The peak-to-peak modulation is about $4 \mathrm{kPa}$. The signal for port 15 was already discussed above, and shows the strongest modulation of $7 \mathrm{kPa}$ peak-to-peak.

\section{QUASI-UNSTEADY COMPUTATIONAL MODEL}

A two dimensional computer simulation of the test section was made to aid in the running of the experimental program. The basic process was to make a series of steady solutions with the oscillating blade in the various positions of its oscillatory motion. These solutions are then linked together, in a 




Fig. 12. Effects of blade oscillation frequency for inlet Mach number of 0.5 .

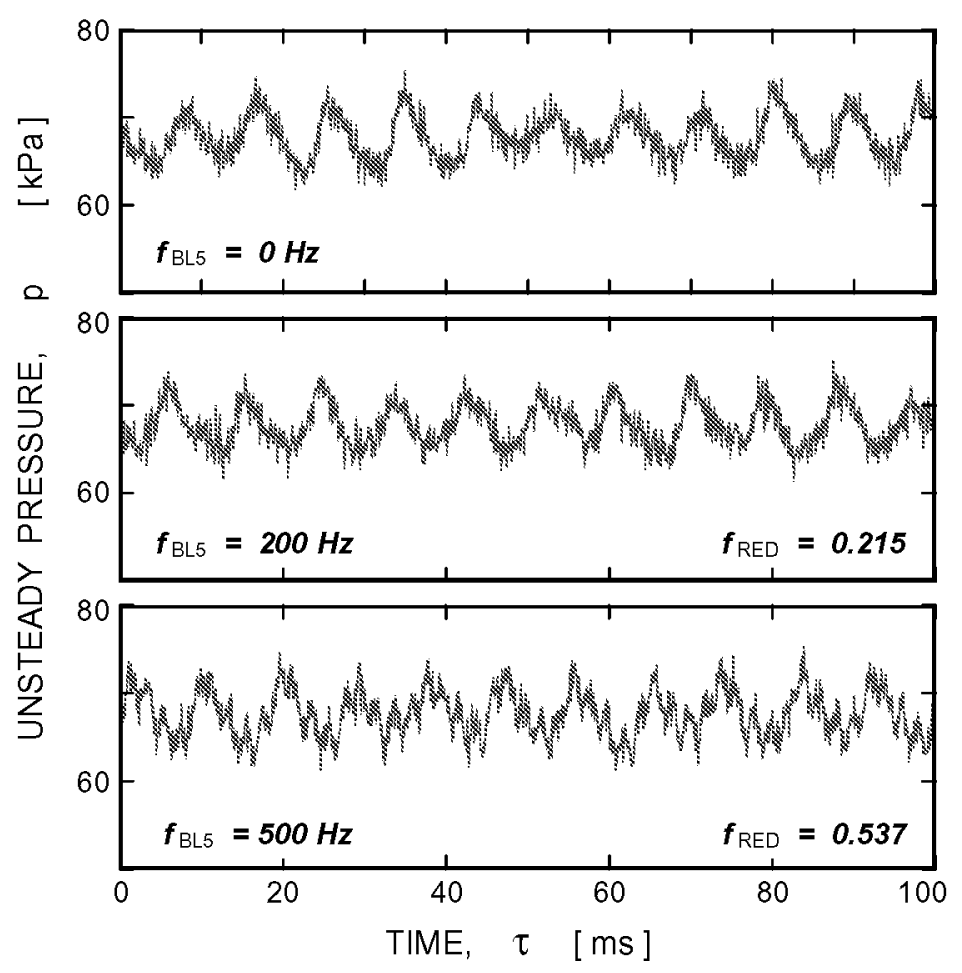

Fig. 13. Effects of blade oscillation frequency for inlet Mach number of 0.8 .

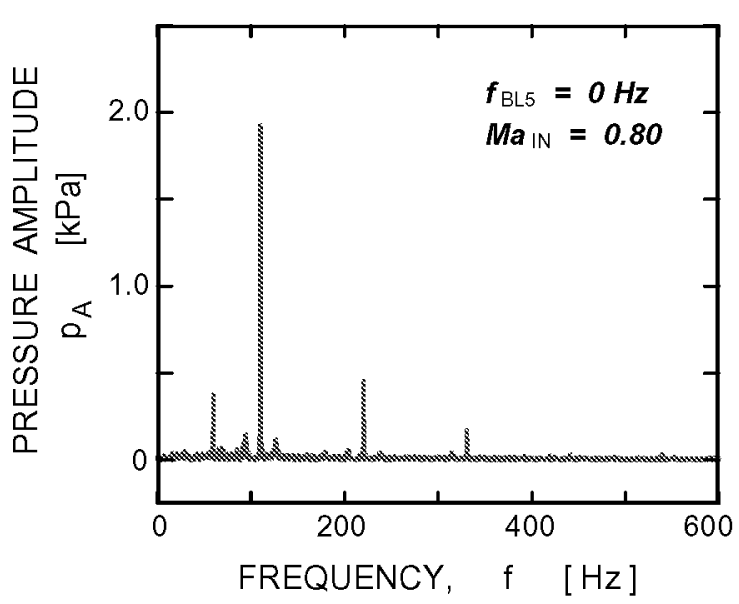

Fig. 14. Frequency spectrum for port 15 on blade BL4 for no blade oscillation.

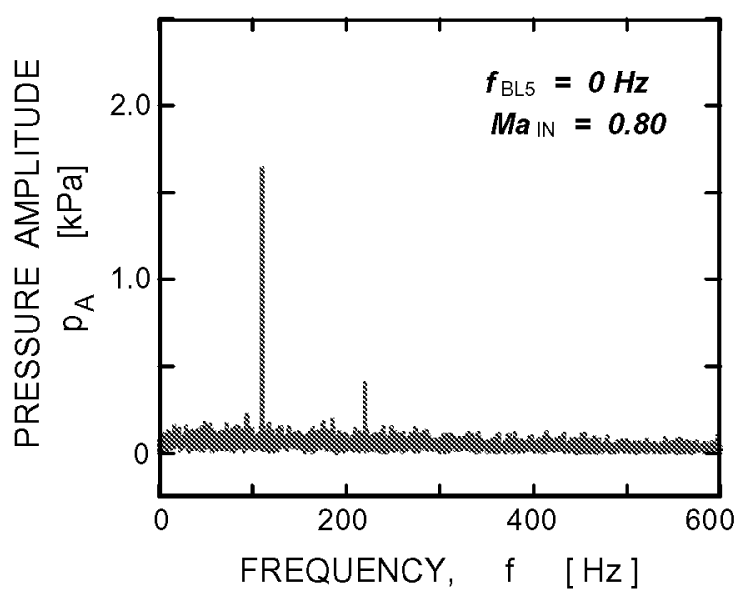

Fig. 15. Frequency spectrum for port 1 on blade BL4 for no blade oscillation.

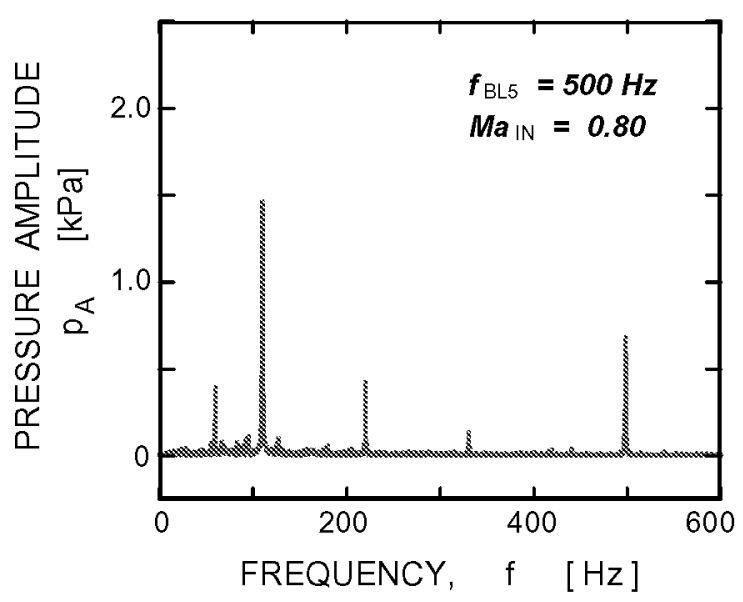

Fig. 16. Frequency spectrum for port 15 on blade BL4 for blade BL5 oscillating at $500 \mathrm{~Hz}$. 

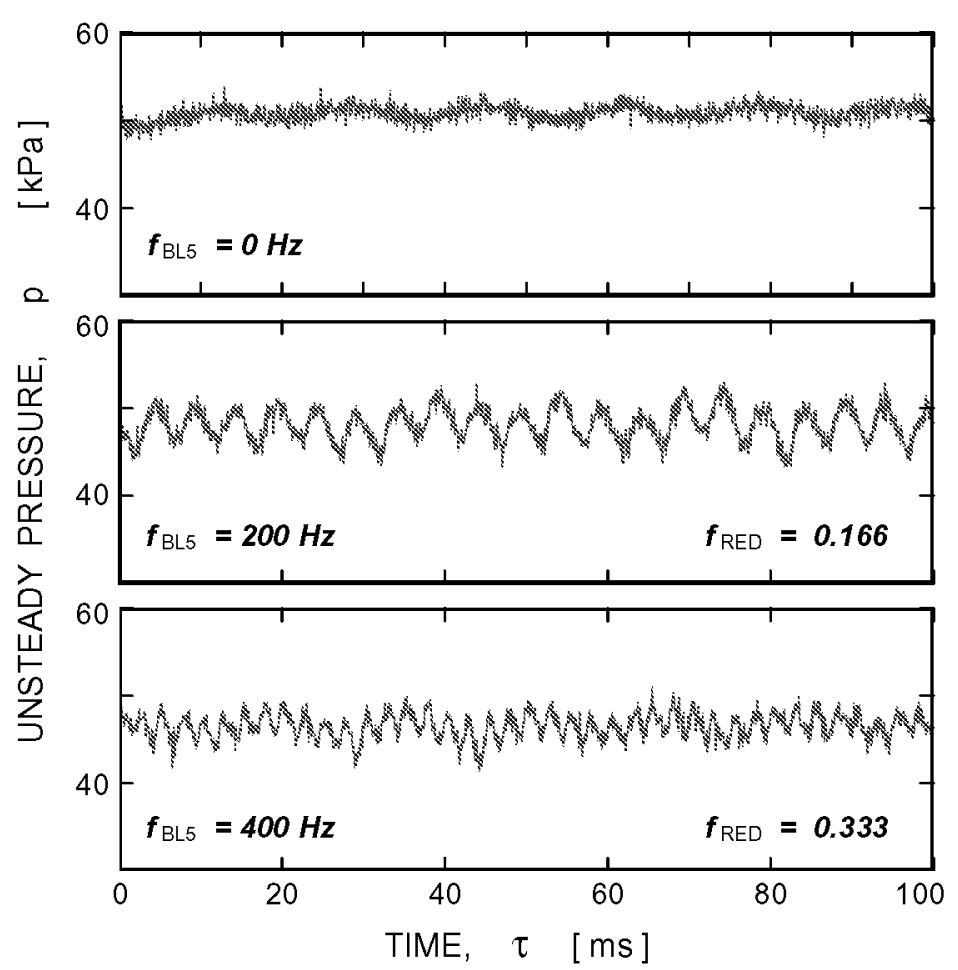

Fig. 17. Effects of blade oscillation frequency for inlet Mach number of 1.08 .

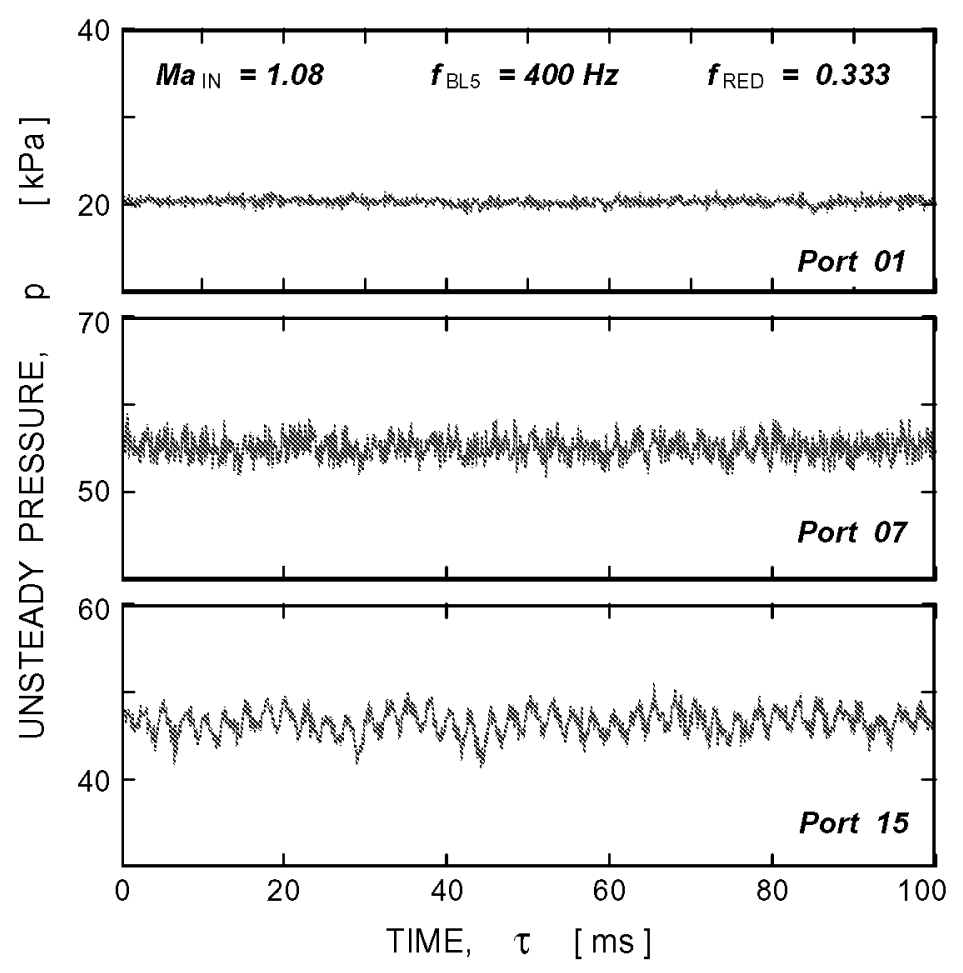

Fig. 18. Effects of position along blade chord on pressure unsteadiness. sequence to produce the quasi-unsteady solution. This technique of approximating the true unsteady solution is also known as a quasi-steady computation or technique. The computational model was based on an integral equation method (Refs. 15,16). The simulation included the nine cascade blades and the tunnel walls. Since the solution technique does not require a computational grid and is very fast running, it provided a means for quickly looking at the effects variations in the test section geometry had on the periodicity of the flow for steady state conditions (Ref. 7). The simulation was modified in order to gain some guidance on flowfield behavior for a single oscillating blade in the cascade. The modification produced a quasi-unsteady simulation of the oscillating flow. The equation of motion of the oscillating blade was added to the simulation. This allowed the position of the blade and its velocity relative to the stationary blades and tunnel walls to be calculated for any arbitrary point in the oscillation cycle. This information was used to alter the previous stationary blade simulation by modifying the surface velocity boundary conditions according to the blades position during an oscillation. The result was an instantaneous look at the potential effect the blade oscillation had on the flow field.

The results of the calculations gave the location and the magnitude of variations in the flow field caused by the moving blade at a specific position in the oscillation cycle. A typical sequence of solutions is shown in Fig. 19. The test condition for the figure is an inlet Mach number of 0.8 , oscillating frequency of $500 \mathrm{~Hz}$, and blade maximum deflection of $0.6 \mathrm{dg}$. The first plot shows the blade at maximum deflection (leading edge moved $0.6 \mathrm{dg}$ to the right), and at zero rotational velocity, as the blade is about to change direction. The second plot shows the blade at maximum deflection to the left. Timing or phasing information cannot be determined from the solutions since time is not a variable in the solution. Any potential effect appears to occur throughout the flow field instantaneously in the calculation.

The entire test matrix for the two subsonic inlet Mach numbers of 0.5 and 0.8 were calculated. Four frequencies $(200,300,400$ and $500 \mathrm{~Hz})$ and three deflection angles $(0.6,1.2$, and $2.4 d g)$ were calculated for these Mach numbers. A summary of the results of the computational simulation is presented in Fig. 20. The plots show variations of root-mean-square (RMS) values of pressure fluctuation for various flow conditions along the suction surface of blade BL4 and along the pressure surface of blade BL6. 


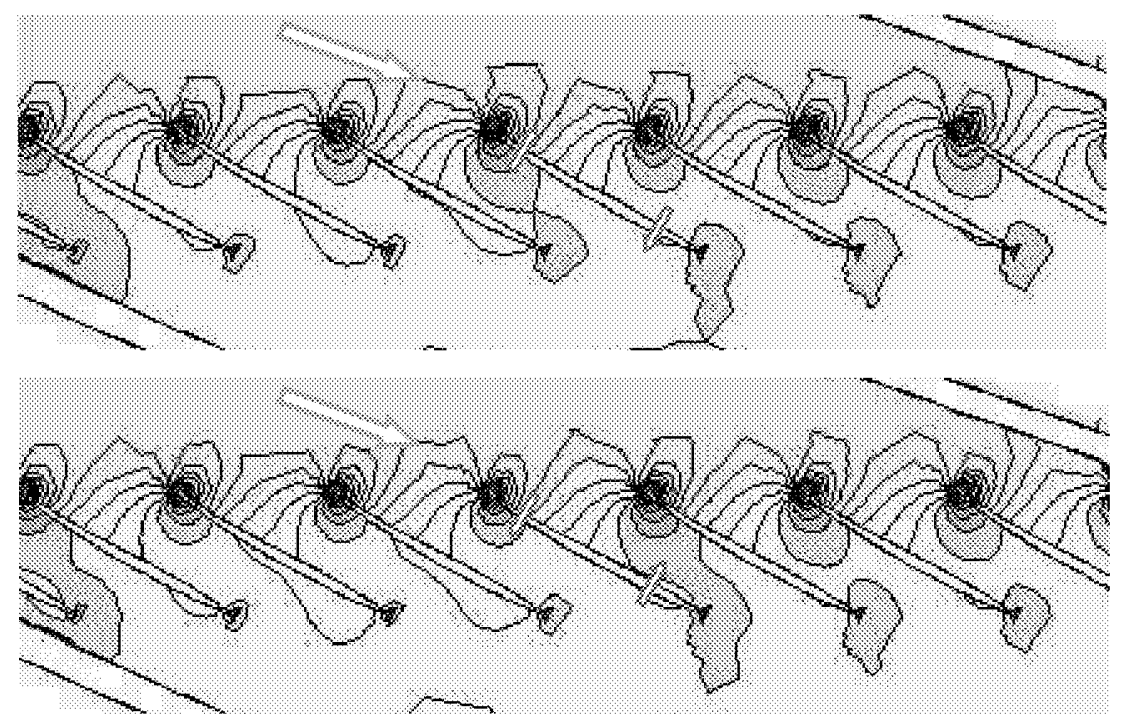

Fig. 19 Quasi-unsteady solution for oscillation amplitude of $0.6 \mathbf{d g}$, inlet Mach number of 0.5 , and frequency of $500 \mathrm{~Hz}$.
AQ $\quad * 0 \% 8 \%$

PRESSURE

SCALE [ $\boldsymbol{k P a}$ ]

100

90

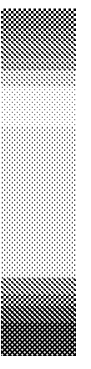

$A Q=-10.8 \%$

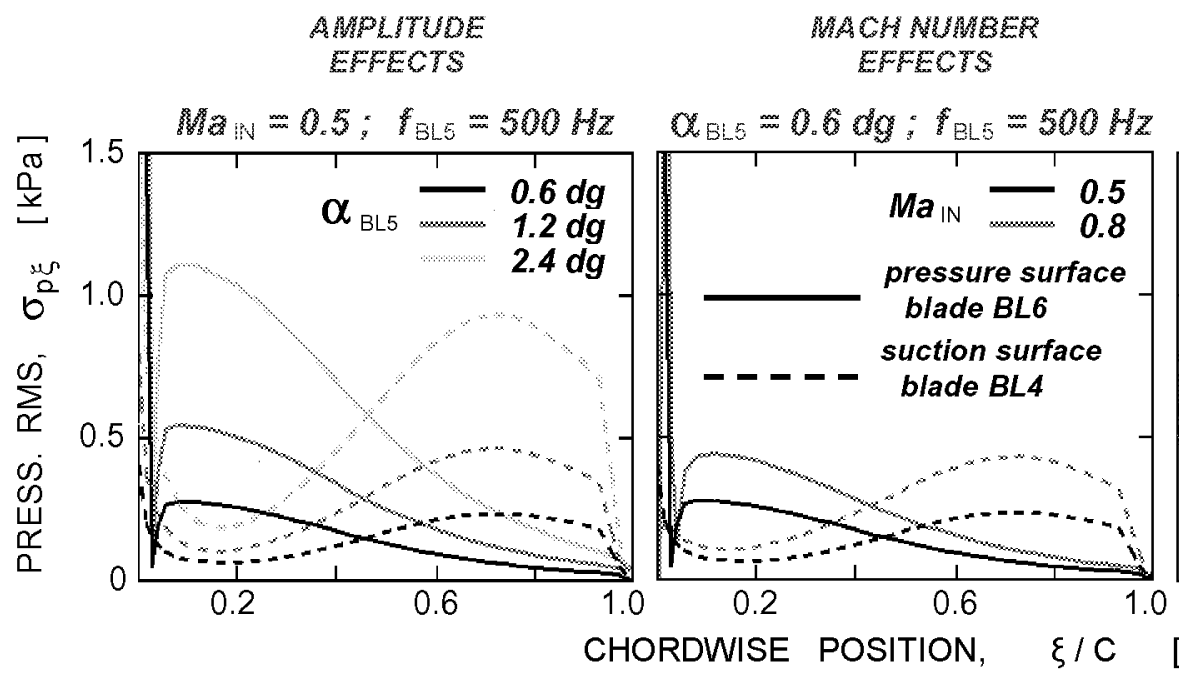

Fig. 20 Summary of CFD predictions.

\section{CORRELATION OF EXPERIMENTAL DATA WITH COMPUTATIONAL PREDICTIONS}

The CFD prediction used in this study was intended as quick look at the overall features of the experimental flow field in order to provide guidance in setting up and running the experiment. A detailed comparison of the CFD simulation and the data was not initially contemplated. However by knowing the limitations of the simulation, a comparison to the data can yield some useful insights into variations and trends in the data. The CFD simulation solves a basically linear flow problem. It does not include any of the nonlinear flow features expected to be found in the actual flow measurements. Viscosity and flow separation are ignored. Compressible flow effects are only approximated in a linear fashion. The time variation in the flow due to blade oscillation is modeled by assembling a series of static solutions with proper surface boundary conditions to reflect the motion of the oscillating blade.

Given the limited level of flow physics modeling used in the CFD computation, one would expect the data to compare with the calculation at test conditions where the flow is varying the least spatially and temporally, compressibility effects are smallest, and flow separation is not present. Also comparisons will be best in regions of the flow where first order flow effects due to such things as flow area change occur. Indeed as will be described below, this is the case. The CFD predictions compare best with the data when the oscillation frequency and inlet Mach numbers are lowest. They also compare well in 
regions of the flow field where flow separation has not occurred, and where the flow is contained within the covered portion of the blade passage. One can deduce from these comparisons that when there is agreement the flow is behaving in a linear, steady manner, and when they do not agree unsteady and/or nonlinear flow effects are present.

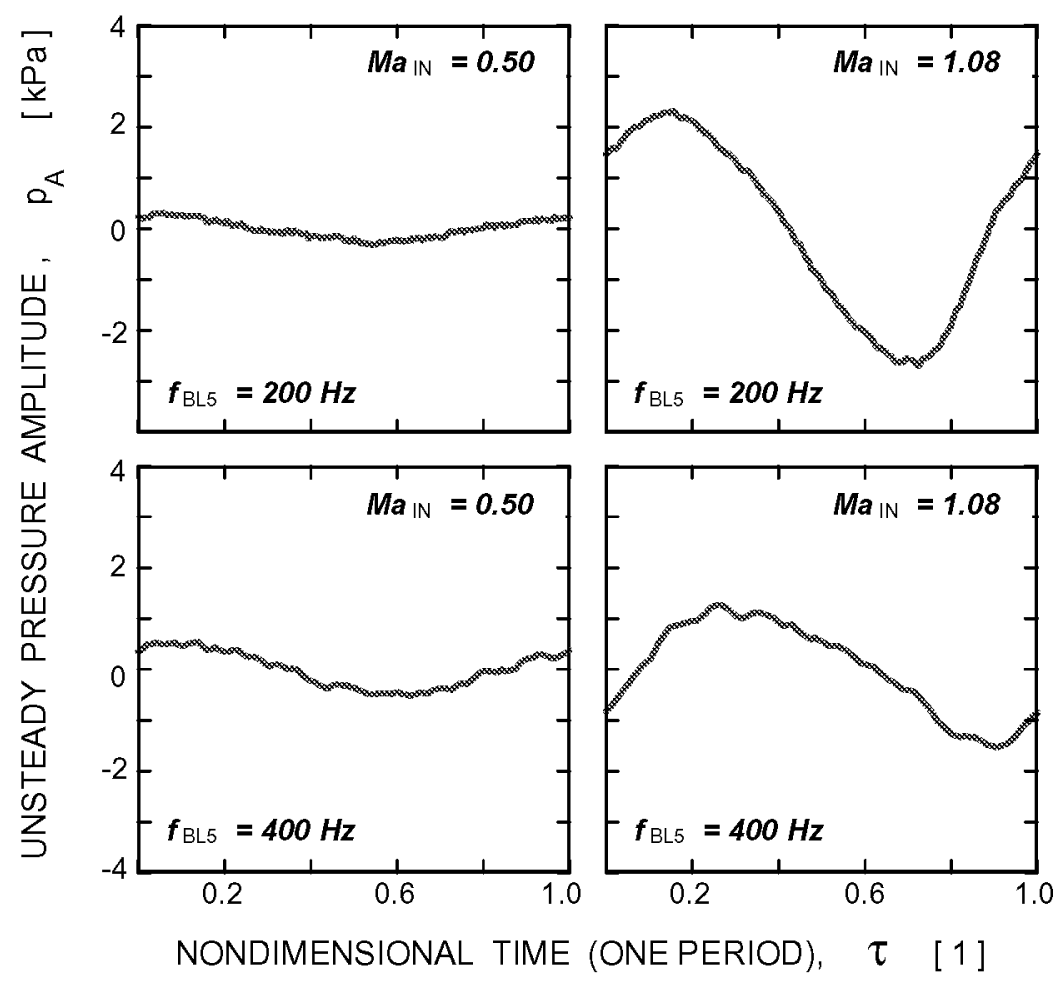

Fig. 21. Mach number and frequency effects on averaged forced pressure fluctuations at port 15 on the suction side of BL4.

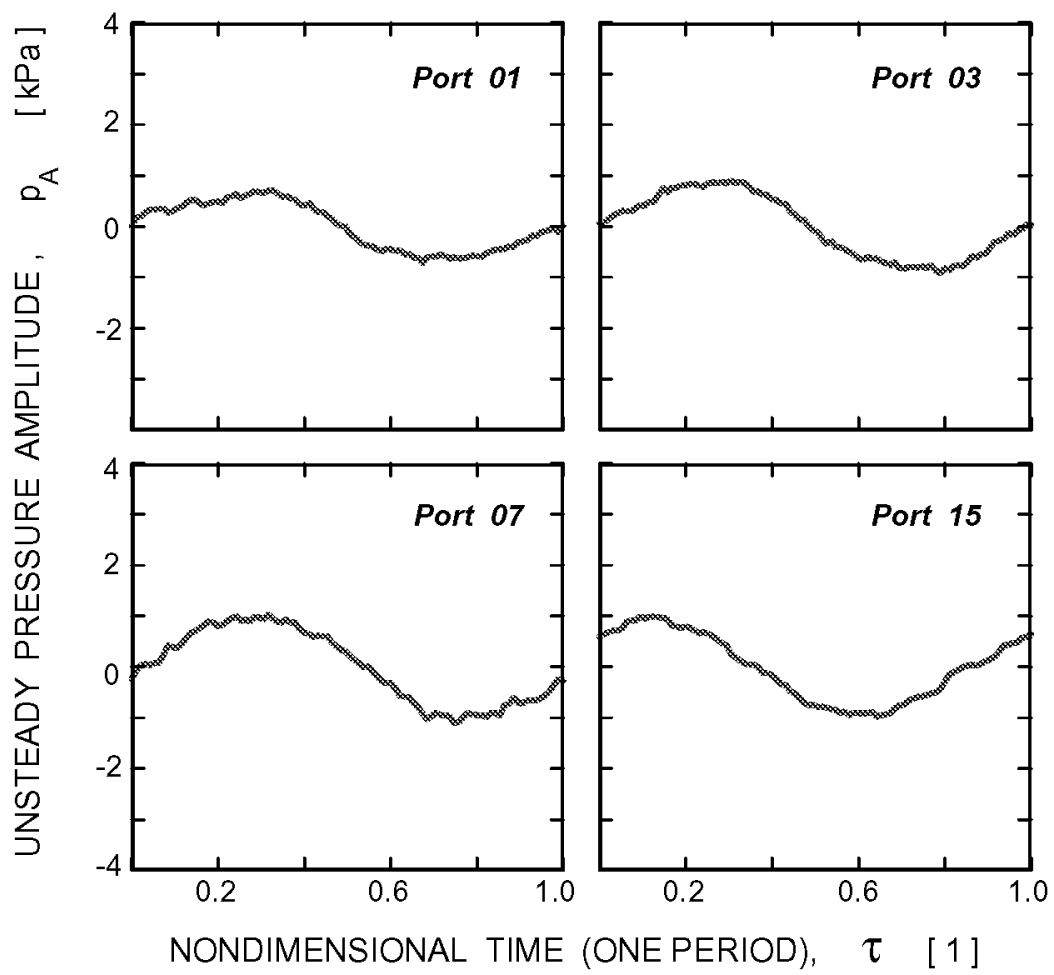

Fig. 22. Averaged forced pressure fluctuations along the suction side of blade BL4 for an inlet Mach number of 0.8 and oscillation frequency of $400 \mathrm{~Hz}$.
To compare experimental data with CFD predictions, the RMS values of forced pressure fluctuations must be extracted from pressure histories. First, the unsteady pressure signals are ensemble averaged over an interval of one period of blade oscillation. The time basis for ensemble averaging is the OPP signal. Ensemble averaging reduces the random pressure fluctuations, but preserves the periodic content of the signal that is phase locked to the basis of averaging; it is the frequency of blade oscillations in this case. Therefore, periodic changes in the signal history that are not phase-locked to the frequency of blade oscillations will also be suppressed. Then, an RMS value of the ensemble-averaged signal is calculated for a period of one blade oscillation. This resulting value is compared with the corresponding predicted value.

The entire 3000-ms long data set was used for ensemble averaging. Consequently, pressure signals acquired for $200 \mathrm{~Hz}$ blade oscillation were averaged over 600 periods, while signals for $500 \mathrm{~Hz}$ oscillation were averaged over 1500 periods. The time resolution is $26 \mu \mathrm{s}$ for all cases. The results of ensemble averaging are shown in Figs. 21 and 22. Data in Fig. 21 are for port 15 (the closest port to the trailing edge) on the suction side of blade BL4. A brief inspection of Fig. 21 reveals that for the inlet Mach number of 0.5 the pressure waves are very weak; a difference in amplitude between the case for $200 \mathrm{~Hz}$ and the case for $400 \mathrm{~Hz}$ forcing frequency is barely visible. For the inlet Mach number of 1.08 , however, the amplitude difference between the cases for these two forcing frequencies is large. Fig. 22 depicts pressure waves for an inlet Mach number of 0.8 and forcing frequency of $400 \mathrm{~Hz}$ for different ports on the suction side of blade BL 4 . It should be pointed out here that ensemble averaging completely suppressed the selfinduced pressure fluctuations detected in the pressure histories in Fig. 13. Obviously, the selfinduced fluctuations are not phase-locked to the forcing frequency.

Fig. 23 compares predicted and measured pressure fluctuations for the suction surface of blade BL4 for two inlet Mach numbers of 0.5 and 0.8 and two forcing frequencies of $200 \mathrm{~Hz}$ and $500 \mathrm{~Hz}$. The prediction for Mach number 0.5 and frequency $200 \mathrm{~Hz}$ agrees extremely well with the experimental data. For the frequency of $500 \mathrm{~Hz}$, however, the trend is predicted correctly, but the amplitude of experimental data is about twice that of the prediction. The predictions indicate no effect of the forcing frequency (Fig. 20); the experimental data 


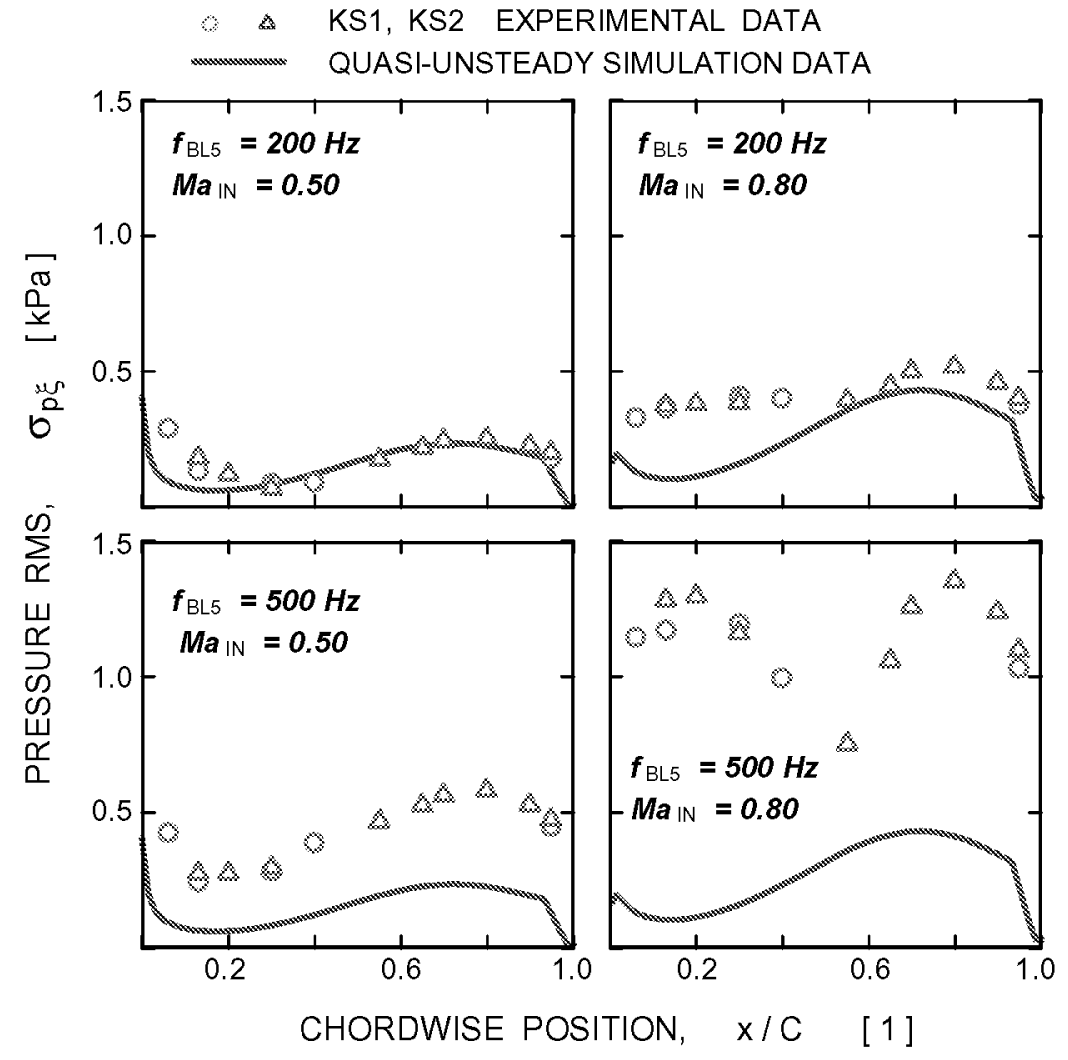

Fig. 23. Mach number and forced frequency effects on average pressure fluctuations on suction side of blade BL4.

$\because$ KP1, KP2 EXPERIMENTAL DATA

QUASI-UNSTEADY SIMULATION DATA

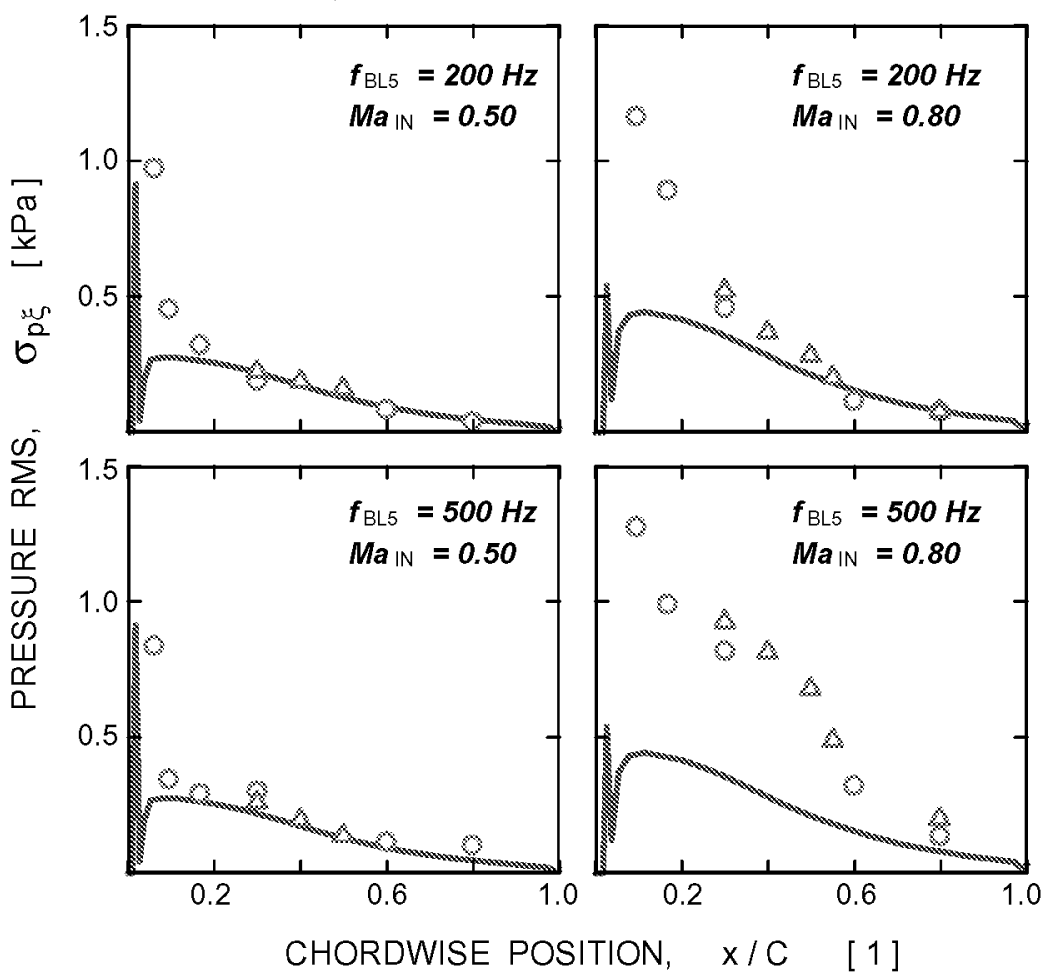

Fig. 24. Mach number and forced frequency effects on average pressure fluctuations on pressure side of blade BL6. contradicts this finding. For the case of inlet Mach number 0.8 , when compressibility strongly affects flow behavior, the experimental data indicate a different trend in the chordwise distribution of pressure fluctuations with a local minimum at the mid portion of the blade. Now, even the upstream half of the blade suction side is subjected to strong pressure fluctuations. This trend was not predicted. For the low forcing frequency of $200 \mathrm{~Hz}$, the prediction and experimental data are quite close over the downstream half of the blade. For the high frequency of $500 \mathrm{~Hz}$, however, the prediction and experimental data are far apart.

A comparison of pressure side predictions with experimental data is in Fig. 24. For the low inlet Mach number of 0.5 the predictions and experimental data are reasonably close for forcing frequency of $200 \mathrm{~Hz}$. For the high inlet Mach number of 0.8 , the measured amplitude of pressure fluctuations is much higher than the predicted one. Again, the experimental data indicate an increase in the amplitude of pressure fluctuations with an increasing frequency, the trend that was not predicted. However, the experiment confirmed the trend of decreasing amplitude of forced pressure fluctuations along the blade pressure side in the direction from the leading to trailing edge.

\section{CONCLUSIONS}

The following conclusions can be drawn from the current phase of the study:

- Pressure data acquired in the NASA TFC over a period of six months and several reconfigurations of the test facility show remarkable repeatability and consistency. This indicates the high quality and reliability of the acquired data sets.

- Time-averaged values of unsteady pressures acquired by miniature pressure transducers agree very well with static tap pressure data acquired by conventional instrumentation, and ensures the accuracy of measured unsteady pressure fluctuation. The accuracy is estimated to be better than $4 \%$ of the local unsteady pressure amplitude.

- Blade surface pressures for low subsonic inlet flow of Mach number 0.5 and low supersonic flow of Mach number 1.1 exhibit very low unsteadiness for cases of no blade oscillations, while for high subsonic flow of Mach number 0.8 for the same condition, blade pressures exhibit very strong self-induced oscillations with an amplitude of $5.5 \mathrm{kPa}$ at a frequency of $110 \mathrm{~Hz}$. The origins of these oscillations are not clear, and it is not obvious, at present, if this is a cascade or tunnel phenomenon. 
-Quasi-unsteady simplified computer simulations gave quick guidance to overall features in the experimental flow field. However the simulation's validity is limited to only the lowest Mach number of 0.5 and forcing frequency of 200 $\mathrm{Hz}$ where the flow field's behavior is most linear and steady in manner.

- For high Mach numbers and oscillation frequencies, strong nonlinear effects govern the flow field's behavior, and the simplified simulation does not capture the physics of the flow phenomena.

- For a fixed forcing frequency, the amplitude of forced pressure fluctuations on neighboring stationary blades increases with an increasing inlet Mach number.

- For subsonic inlet Mach numbers, the amplitude of forced pressure fluctuations on neighboring stationary blades increases with an increasing forcing frequency.

- For a supersonic inlet Mach number of 1.1, the amplitude of forced pressure fluctuations on neighboring stationary blades slightly decreases with an increasing forcing frequency.

- An extensive set of unsteady pressure data was acquired along mid span of a modern transonic fan blade for simulated flutter conditions. This will be essential for development and verification of computer codes for blade flutter effects.

\section{REFERENCES}

1. Buffum, D.H., Capece, V.R., King, A.J., and El-Aini, Y.M.: "Oscillating Cascade Aerodynamics at Large Mean Incidence", ASME Paper 96-GT-339; also NASA TM107247, 1996.

2. Lepicovsky, J., McFarland, E.R., Chima, R.V, and Wood, J.R.: "On Flowfield Periodicity in the NASA Transonic Flutter Cascade", Journal of Turbomachinery, Vol. 123, pp. 501-509, 2001.

3. Boldman, D.R. and Buggele, A.E.: "Wind Tunnel Tests of a Blade Subjected to Midchord Torsional Oscillations at High Subsonic Stall Flutter Conditions", NASA TM78998, 1978.

4. Shaw, L.M., Boldman, D.R., Buggele, A.E., and Buffum, D.H.: "Unsteady Pressure Measurements on a Biconvex Airfoil in a Transonic Oscillating Cascade", Journal of Engineering for Gas Turbines and Power, Vol. 108, pp. 53-59, 1986.
5. Buffum, D.H., Capece, V.R., King, A.J., and El-Aini, Y.M.: "Experimental Investigation of Unsteady Flows at Large Incidence Angles in a Linear Oscillating Cascade", AIAA Paper 96-2823; also NASA TM-107283, 1996.

6. Lepicovsky, J., McFarland, E.R., Chima, R.V, and Wood, J.R.: "On Flowfield Periodicity in the NASA Transonic Flutter Cascade, Part I - Experimental Study", ASME Paper 2000-GT-0572, 2000.

7. Chima, R.V, McFarland, E.R., Wood, J.R., and Lepicovsky, J.: "On Flowfield Periodicity in the NASA Transonic Flutter Cascade, Part II - Numerical Study", ASME Paper 2000-GT-0573, 2000

8. Lepicovsky, J., Chima, R.V., Jett, T.A., Bencic, T.J., and Weiland, K.E.: "Investigation of Flow Separation in a Transonic-Fan Linear Cascade Using Visualization Methods," International Symposium on Flow Visualization, Paper 335, 2000.

9. Buffum, D.H. and Fleeter, S.: "Wind Tunnel Wall Effects in a Linear Oscillating Cascade", NASA TM-103690, 1991.

10. Gerolymos, G.A.: "Periodicity, Superposition, and 3D Effects in Supersonic Compressor Flutter Aerodynamics," International Journal of Turbo and Jet Engines, Vol. 7, pp. $143-152,1990$.

11. Buffum, D.H. and Fleeter, S.: "Oscillating Cascade Aerodynamics by an Experimental Influence Coefficient Technique," AIAA Journal of Propulsion and Power, Vol. 6, No. 5, pp. 612-620, 1990.

12. Bolcs, A., Fransson, T.H. and Schlafi, D.: "Aerodynamic Superposition Principle in Vibrating Turbine Cascades," AGARD-CPP-468/469, pp. 5-1 to 5-19, 1990.

13. Fransson, T.H.: "Analysis of Experimental TimeDependent Blade Surface Pressures from an Oscillating Turbine Cascade with the Influence-Coefficient Technique," ASME Paper No. 90-GT-225, 1990.

14. Lepicovsky, J., McFarland, E.R., Capece, V.R., Jett, T.A., and Senyitko, R.G.: "Methodology of Blade Unsteady Pressure measurement in the NASA Transonic Flutter Cascade," NASA TM-TBD, 2002.

15. McFarland, E.R.: "A Rapid Blade-to-Blade Solution for Use in Turbomachinery Design," Journal of Engineering for Power, Vol. 106, pp. 376-382, 1984.

16. McFarland, E.R.: "An Integral Equation Solution for Multistage Turbomachinery Design Calculations," ASME Paper 93-GT-41, 1993. 


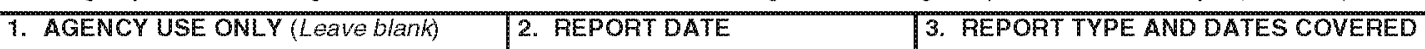

\begin{tabular}{|c|c|c|}
\hline & July 2002 & Technical Memorandum \\
\hline
\end{tabular}

\begin{tabular}{l|l|l} 
4. TITLE AND SUBTITLE & 5. FUNDING NUMBERS
\end{tabular}

Unsteady Pressures in a Transonic Fan Cascade Due to a Single

Oscillating Airfoil

6. ALTHOR(S)

WU-708-28-13-00

J. Lepicovsky, E.R. McFarland, V.R. Capece, and J. Hayden

7. PERFORMING ORGANIZATION NAME(S) AND ADDRESS(ES)

National Aeronautics and Space Administration

John H. Glenn Research Center at Lewis Field

Cleveland, Ohio 44135-3191

9. SPONSORING/MONITORING AGENCY NAME(S) AND ADORESS(ES)

10. SPONSORING/MONITORING AGENCY REPORT NUMBER

National Aeronautics and Space Administration

Washington, DC 20546-0001

NASA TM-2002-211723

GT--2002--30312

\section{SUPPLEMENTARY NOTES}

Prepared for the Turbo Expo 2002 cosponsored by the American Society of Mechanical Engineers and the International Gas Turbine Institute, Amsterdam, The Netherlands, June 3-6, 2002. J. Lepicovsky, QSS Group, Inc., Cleveland, Ohio 44135; E.R. McFarland, NASA Glenn Research Center; V.R. Capece and I. Hayden, University of Kentucky, Department of Mechanical Engineering, Paducah, Kentucky 42002. Responsible person, J. Lepicovsky, organization code 5810 , $216-433-1402$

\begin{tabular}{l|l} 
12a. DISTRIBUTION/AVAILABILITY STATEMENT & 12b. DISTRIBUTION CODE
\end{tabular}

Unclassified-Unlimited

Subject Category: 07

Distribution: Nonstandard



This publication is available from the NASA Center for AeroSpace Information, 301-621-0390.

13. ABSTRACT (Maximum 200 words)

An extensive set of unsteady pressure data was acquired along the midspan of a modern transonic fan blade for simulated flutter conditions. The data set was acquired in a nine-blade linear cascade with an oscillating middle blade to provide a database for the influence coefficient method to calculate instantaneous blade loadings. The cascade was set for an incidence of 10 dg. The data were acquired on three stationary blades on each side of the middle blade that was oscillated at an amplitude of $0.6 \mathrm{dg}$. The matrix of test conditions covered inlet Mach numbers of $0.5,0.8$, and 1.1 and the oscillation frequencies of $200,300,400$, and $500 \mathrm{~Hz}$. A simple quasiunsteady two-dimensional computer simulation was developed to aid in the running of the experimental program. For high Mach number subsonic inlet flows the blade pressures exhibit very strong, low-frequency, self-induced oscillations even without forced blade oscillations, while for low subsonic and supersonic inlet Mach numbers the blade pressure unsteadiness is quite low. The amplitude of forced pressure fluctuations on neighboring stationary blades strongly depends on the inlet Mach number and forcing frequency. The flowfield behavior is believed to be governed by strong nonlinear effects due to a combination of viscosity, compressibility, and unsteadiness. Therefore, the validity of the quasi-unsteady simplified computer simulation is limited to conditions when the flowfield is behaving in a linear, steady manner. Finally, an extensive set of unsteady pressure data was acquired to help development and verification of computer codes for blade flutter effects.

14. SUBJECT TERMS

Machines for compressing air or other fluids

15. NUMBER OF PAGES

18

16. PRICE CODE

\section{LIMITATION OF ABSTRACT}

\begin{tabular}{|c|c|c|}
\hline $\begin{array}{l}\text { 17. SECURITY CLASSIFICATION } \\
\text { OF REPORT }\end{array}$ & $\begin{array}{l}\text { 18. SECURITY CLASSIFICATION } \\
\text { OF THIS PAGE }\end{array}$ & $\begin{array}{l}\text { 19. SECURITY CLASSIFICATION } \\
\text { OF ABSTRACT }\end{array}$ \\
\hline Unclassified & Unclassified & Unclassified \\
\hline
\end{tabular}

NSN 7540-01-280-5500
Standard Form 298 (Rev. 2-89)

Prescribed by ANSI Std. Z39-18 298-102 